\title{
O EU ENTRE FREUD E LACAN
}

\author{
Allysson Alves Anhaia ${ }^{1}$
}

\begin{abstract}
RESUMO: O objetivo deste artigo é explicitar as diferenças da noção de eu no que se refere à segunda tópica freudiana e aos primeiros anos de ensino de Lacan. Para tal, abordaremos a formação do psiquismo humano de acordo com o que Freud organiza na segunda tópica, passando por conceitos como inconsciente, pré-consciente e consciente, bem como os princípios de prazer e de realidade. Após isso, abordaremos a constituição do eu imaginário de Lacan e mostraremos de que forma esse eu, por mais que o psicanalista francês afirme ser este como o eu freudiano, distancia-se e diferencia-se do de Freud.
\end{abstract}

Palavras-chave: Eu; Imaginário; Inconsciente.

\section{THE I BETWEEN FREUD AND LACAN}

ABSTRACT : The aim of this article is to clarify the differences in the notion of I in relation to the second Freudian topic and the first years of Lacan's teaching. For this, we will discuss the formation of the human psyche according to what Freud organizes in the second topic, going through concepts such as unconscious, pre-conscious and conscious, as well as the principles of pleasure and reality. After this, we will discuss the constitution of the imaginary I of Lacan and show how this I, even though the french psychoanalyst asserts itto be as the Freudian I, distances itself and differs from that of Freud.

Keywords: I; Imaginary; Unconscious.

\section{INTRODUÇÃO}

A noção de eu advinda da psicanálise adquiriu com o tempo o aspecto de ser uma das mais importantes contribuições para se pensar a constituição do sujeito e sua subjetividade, de forma que se faz pertinente uma investigação de tal noção em dois dos principais psicanalistas do século $\mathrm{XX}$, tanto para um conhecimento mais abrangente da origem da psicanálise e de seus termos, quanto para o conhecimento da história da psicanálise de modo geral. Sendo assim, este artigo tem por objetivo percorrer o trajeto que vai desde a formação do Eu na segunda tópica freudiana até a formação do eu imaginário nos primeiros anos do ensino de Lacan, com o intuito de entender o que provocou e no que se constituem as diferenças das noções de eu na literatura dos dois

\footnotetext{
${ }^{1}$ Mestrando em filosofia pela Pontifícia Universidade Católica do Paraná. E-mail: zubualves@gmail.com 
psicanalistas. Para isso, se fará necessária a abordagem da formação da segunda tópica de Freud nas obras Além do Princípio do Prazer (2010) e O Eu e o Id (2011), a fim de explicitar a formação do psiquismo humano, a constituição e o lugar do Eu em meio a este. O enfoque, no que diz respeito ao eu lacaniano, se dará a partir do escrito do Estádio do Espelho (1998) e o Seminário Livro 2 (2010), de maneira que se evidencie o movimento, feito por Lacan, que retira das entrelinhas dos conceitos freudianos a noção de um eu imaginário.

\section{O EU FREUDIANO}

A novidade da psicanálise ${ }^{2}$, inaugurada por Freud, foi articulada de maneira que não coloca a essência do psiquismo na consciência, uma vez que ela é obrigada a ver essa consciência como apenas mais uma qualidade ${ }^{3}$ do psíquico, que pode juntar-se a outras qualidades ou até mesmo estar ausente. É por conta disso que, de acordo com Jorge (2017, p. 15), as teses freudianas sofreram recusas acentuadas em seus anos iniciais, já que traziam à tona uma verdade inaceitável e insuportável para os humanos uma vez que demonstraram que há neles algo que os faz agir contra a sua vontade consciente e, em alguns casos, sem saber o que fazem.Isso ocorre no âmbito da segunda tópica, a partir da divisão que o psicanalista elabora entre Eu,Id e Super-eu.Para abordar essa divisão de maneira clara faz-se necessário compreender também a distinção entre o inconsciente e a consciência na obra Freudiana.Segundo Freud (2011, p. 16), estar consciente é uma "expressão puramente descritiva que invoca a percepção imediata e segura." Isso porque uma ideia, por exemplo,não é consciente de forma duradoura, isto é, ela só é consciente no momento em que é o foco do pensamento ou da atenção do indivíduo, de maneira que é típico que isso mude rapidamente: uma ideia que agora é consciente já não é mais no momento seguinte.Quando algo pode fazer esse movimento

\footnotetext{
${ }^{2}$ Sabe-se que o conteúdo da psicanálise freudiana pode, de certa forma, ser encontrado também nas obras de Schopenhauer e Nietzsche, com o primado da Vontade sobre a consciência, por exemplo. Entretanto, a novidade da psicanálise se faz a partir da sistematização do psiquismo humano com a dualidade do inconsciente e a consciência, como será abordado no decorrer do artigo.

${ }^{3}$ O termo qualidade é utilizado por Freud a partir da virada de 1920, início de sua segunda tópica, na qual a consciência e o inconsciente têm a característica de serem adjetivos. Entretanto, antes dessas obras, na primeira tópica freudiana, essas duas instâncias eram definidas como lugares e temporalidades diferentes. Segundo Câmara (2010, p. 21) "a segunda tópica não anula a primeira, mas aumenta o poder da psicanálise para explicar os fatos psíquicos”.
}

Programas de Pós-Graduação em Ciências Sociais e Filosofia - UNIOESTE - Rua da Faculdade 645. Toledo - PR. CEP 85.903-000 Email: revistaalamedas@gmail.com 
de troca entre não estar e estar consciente, quando pode a qualquer momento vir a ser consciente, diz-se que esse algo, quando não está consciente, é latente. Esse estado latente pode ser descrito, em Freud, como um estado inconsciente, mesmo que ao se falar de um estar inconsciente possa se falar de uma outra maneira, que é a do inconsciente reprimido. Isso se dá a partir de processos psíquicos que podem se tornar conscientes como ideia, mas não por si só, porque uma certa força ${ }^{4}$ se impõe a esses processos, fazendo-os, antes de se tornarem conscientes, reprimidos. Assim, em Freud, tem-se dois inconscientes: o latente e o reprimido, dos quais o primeiro é descritivamente inconsciente e capaz de consciência, enquanto o segundo não.

Assim sendo, o psicanalista inicia a distinção da psique do indivíduo em três instâncias: o consciente, o pré-consciente - que nada mais é do que o inconsciente latente - e o inconsciente, que agora não é puramente descritivo e se limita ao reprimido. Vale ressaltar, apoiado por Jorge (2017, p. 16), que ao dar destaque ao inconsciente o psicanalista trata de assuntos como sonhos, chistes e o esquecimento, que até então eram tidos como menos importantes para o discurso da ciência e da medicina, e encontra um caminho de acesso para uma verdade que o indivíduo até então não tinha acesso conscientemente. Para Freud, a consciência é a superfície do aparelho psíquico, de forma que ela é caracterizada por todas as percepções exteriores, pelos sentimentos e sensações interiores. Entretanto, em relação aos processos que se referem ao inconsciente, só podemos conhecê-los a partir do momento em que eles se tornam conscientes, e isso acontece por intermédio do pré-consciente, pelas ligações com as representações verbais correspondentes. Segundo o inventor da psicanálise (FREUD, 2011, p. 24), "essas representações verbais ${ }^{5}$ são resíduos de memórias; foram uma vez percepções e, como todos os resíduos mnemônicos, podem voltar a ser conscientes." Por isso, o pré-consciente funciona como um intermediário entre o inconsciente e a consciência, é ele que tem as chaves para representar os processos que acontecem no inconsciente sem representação.

\footnotetext{
${ }^{4}$ Essa força atua por intermédio da castração. Ela faz referência, em Freud, à figura paterna no mito do Édipo, que é o representante da lei para o indivíduo, tendo como instância de partida o Super-eu. Já em Lacan, essa força pode ser entendida a partir do nome-do-pai, que, à maneira da figura paterna do Édipo, permite ao sujeito a simbolização da lei.

${ }^{5}$ Vale ressaltar que, em Freud, essas representações verbais derivam de resíduos que se encontram no pré-consciente e que são sempre resultado de percepções acústicas, de forma que o pré-consciente freudiano pode ser caracterizado como que uma origem sensorial especial.
} 
A partir dessa tríade Freud articula a sua noção do psiquismo, na qual chamará de Eu a instância que parte e que é inicialmente pré-consciente, mas que também é capaz de ligar-se ao consciente, de fazer a descarga de excitações no mundo externo e a censura dos sonhos. Esse Eu freudiano, assim como pontua Câmara (2010, p. 21), é sobretudo corporal, uma projeção psíquica da superfície do corpo, e se origina do contato do indivíduo com o mundo exterior.A instância que se liga e se comporta como o inconsciente é chamada de $\mathrm{Id}^{6}$. É a partir dessa distinção que a novidade da psicanálise começa a tomar forma: agora o indivíduo é tido como esse Id, como um algo psíquico que é irreconhecido e inconsciente, em cuja superfície está o Eu que parte do pré-consciente para a consciência. Assim, o psicanalista tira do indivíduo sua característica de reconhecimento com a consciência e com a racionalidade e coloca em um algo que é justamente o seu oposto. Isso fica claro na metáfora que ela propõe (FREUD, 2011, p. 31):

\begin{abstract}
A importância funcional do Eu se expressa no fato de que normalmente lhe é dado o controle dos acessos à motilidade. Assim, em relação ao Id ele se compara ao cavaleiro que deve por freios à força superior do cavalo, com a diferença de que o cavaleiro tem que fazê-lo com suas próprias forças, e o Eu com forças emprestadas. Este símile pode ser levado um pouco adiante. Assim como o cavaleiro a fim de não se separar do cavalo, muitas vezes tem de conduzi-lo aonde ele quer ir, também o Eu costuma transformar em ato a vontade do Id, como se fosse sua própria.
\end{abstract}

Sendo assim, o Eu freudiano é apenas mais uma parte de um sistema maior que compõe o indivíduo, uma parte corporal, responsável por captar as sensações externas e dar vazão as internas, é superficial e por si só a projeção de uma superfície. Não obstante, Freud acrescenta mais uma instância além do Eu e do Id, uma instância que têm menos relação com a consciência, que é algo de elevado, que é o representante da relação do indivíduo com os pais porque é o herdeiro do complexo de Édipo ${ }^{7}$ (FREUD,

\footnotetext{
${ }^{6}$ Ich, no original. Preferimos, nesse artigo,seguir a tradução de Paulo Cezar de Souza como Id, de maneira a conservar a novidade proposta pelo psicanalista a partir desse termo e para conservar a referência a Groddeck. Ver o capítulo "Ich/ego/moi, Es/id/ça",da obra As palavras de Freud: O vocabulário freudiano e suas versões (São Paulo, Ática, 1998, p. 88-95).

${ }^{7}$ Sem dúvidas, o complexo de Édipo é um dos pontos-chave da literatura freudiana. Entretanto, não deve ser entendido de maneira literal: ao se apropriar do mito que narra o assassinato do pai cometido pelo filho que é motivado pelo desejo pela mãe, Freud visa a destacar a característica da simbolização da lei e da castração a partir do interdito do incesto. O mito de Édipo se dá, na obra de Freud, como o início da simbolização do indivíduo.
} 
2011, p. 45) e que nasce de uma identificação com o modelo do pai. Essa instância é o Super-eu $^{8}$, o herdeiro dos mais poderosos impulsos e destinos libidinais, de forma que, enquanto o Eu é o representante do mundo exterior, o Super-eu é o do Id, do mundo interior. Podemos entender o Super-eu como aquele que abriga os sentimentos sociais do indivíduo, as suas identificações com os outros. Segundo Žižek (2010, p. 99), o Super-eu é uma agência ética cruel e sádica que nos faz exigências impossíveis para depois observar o nosso fracasso alegremente. De todo modo, essa agência não é punitiva apenas em relação ao fracasso, mas também em relação a sucessos e vitórias, de maneira que ela imprime a culpa no indivíduo que é capaz de realizar suas exigências. Esse sentimento é resultado da tensão entre o Eu e o Super-eu, na qual se expressa uma condenação do Eu por sua instância crítica. O Super-eu é uma agência que age de maneira inconsciente, mas que, como destaca Freud (2011, p. 66), não pode negar sua origem no que foi ouvido, já que é parte do $\mathrm{Eu}$ e continua acessível à consciência a partir das representações verbais. Contudo, essas representações não chegam ao Super-eu através da percepção auditiva, da leitura ou de explicações e instruções, por exemplo, mas chegam a ela através de fontes que se encontram no interior do Id.

Além dessa distinção tripartite do psiquismo humano, o psicanalista evidencia a posição do homem em meio da tensão que existe entre o princípio do prazer e o da realidade, dos quais o primeiro é o modo de funcionamento primário do aparelho psíquico a partir dos instintos sexuais, enquanto o segundo faz referência aos instintos do Eu. Segundo Burgarelli (2007, p. 215), Freud fundamenta o curso de seus processos psíquicos na tendência à estabilidade de Fechner. Isso significa que, em Freud, o aparelho psíquico é sempre incitado por tensões desprazerosas, de forma que o princípio do prazer toma para si a função de abaixamento dessas incitações com o objetivo de evitar o desprazer e gerar prazer. Já o princípio da realidade também tem como função a obtenção de prazer, mas exige o adiamento e a renúncia da satisfação, além da aceitação de um desprazer temporário ${ }^{9}$. O princípio do prazer evoca no indivíduo, por intermédio

\footnotetext{
${ }^{8}$ Do original Über-ich. Preferimos utilizar a tradução como Super-eu porque mantém o destaque no "eu", como no original.

${ }^{9}$ Vale ressaltar a herança que os princípios do prazer e da realidade têm em relação ao princípio da inércia, apresentado no Projeto de uma psicologia (1985), datado de 1895, mas publicado apenas em 1950. Essa herança se dá porque o aparelho psíquico apresentado no Projeto parece ter toda a sua 
dos instintos sexuais, o desejo pela vida, uma vez que eles "reproduzem os estados primitivos do vivente, mas o objetivo que perseguem com todos os meios é a fusão de duas células germinativas diferenciadas de certa maneira" (FREUD, 2011, p. 211). Isso porque, para o autor, a não união dessas células implica na morte da célula germinativa e de outras células de um organismo multicelular, de maneira que a união prolonga a vida e pode empregar aspecto de imortalidade, de forma que o princípio do prazer é o lugar da pulsão de vida. Em contrapartida, o princípio de realidade faz referência à pulsão de morte, já que ela é um arranjo de convivência, isto é, a morte é uma adaptação às condições da vida externa, uma vez que, desde a divisão das células, uma ilimitada duração da vida individual se tornaria um luxo inconveniente. Assim, como salienta Burgarelli (2007, p. 216), o princípio do prazer é substituído pelo princípio da realidade, em um movimento em que caberia ao primeiro dirigir de "maneira correta" as ameaças de perigo e as exigências pulsionais.

Temos assim, em Freud, um Eu que se vale de todas as percepções que vêm de fora, mas que têm como outro mundo exterior o Id, do qual os conteúdos podem chegar ao Eu de duas maneiras: uma direta e outra pelo Super-eu, além de estar dividido entres os princípios do prazer e de realidade. Dessa maneira, o Eu se desenvolve, segundo Freud (2011, p. 70), “como uma pobre criatura submetida a uma tripla servidão, que sofre com a ameaça de três perigos: do mundo exterior, da libido do Id e do rigor do Super eu", de forma que esse Eu é agora a sede da angústia. Isso acontece porque o Eu tem a pretensão de mediar o mundo exterior para o Id, de maneira a fazê-lo obediente ao mundo e em contrapartida fazer o mundo considerar o desejo do Id. Entretanto, o que acontece é que o Eu se torna o escravo do Id, por conta se sua posição de guia submisso, na qual ele se oferece ao Id para guiar seu desejo em direção ao mundo exterior e acaba assumindo esse desejo para si. Em relação ao Super-eu, o Eu freudiano cultiva a angústia da consciência moral, pela a internalização da lei e da castração, além do medo da morte, que pode surgir pelo abandono de si frente à agressividade do Super-eu, que

arquitetura projetada para que a diferença de quantidade $(Q)$ seja igual a zero. Isso deriva da ancoragem que Freud faz de seu projeto a uma lei geral do movimento, mais precisamente ao princípio da inércia. Isso fica claro na afirmação do autor de "que [o] n[eurônio] aspira libertar-se de Q" (FREUD, 1995, p.10), o que, em outras palavras, quer dizer que o aparelho neuronal visa a manter inalterada a diferença entre repouso e movimento e, consequentemente, entre prazer e desprazer. É interessante identificar a presença da questão do repouso e do movimento, ainda que com uma importância menor do que adquire a partir da virada conceitual para a segunda tópica com as noções de princípio do prazer e realidade.

Programas de Pós-Graduação em Ciências Sociais e Filosofia - UNIOESTE - Rua da Faculdade 645. Toledo - PR. CEP 85.903-000 Email: revistaalamedas@gmail.com 
como herdeiro do Édipo assume a função de protetor e salvador que tinha o pai. Conclui-se assim a construção do Eu de Freud, ligada à consciência e ao inconsciente. Ele é a parte do inconsciente que se modificou, pelo contato com o mundo exterior, de maneira que é ele o mediador e que coloca em conflito os princípios de realidade e de prazer. Uma outra parte desse Eu se constitui como agente crítico e como uma instância separada e autônoma: o Super-eu que assume as funções de ideal do eu, autoobservação e consciência moral.

\section{O EU IMAGINÁRIO}

Entretanto, mesmo que Freud seja o responsável por essa descentralização do sujeito e pela mudança de perspectiva do consciente para os impulsos inconscientes, não foi ele quem definiu o sujeito da psicanálise. A tese aqui presente é a de que, assim como salienta Barroso (2012, p. 149), ainda que a noção de sujeito na psicanálise remonte à teoria freudiana (mesmo que nela careça de definição formal), ela surge nas entrelinhas dessa teoria como uma contraposição ao cogito cartesiano e à supremacia do consciente. É somente em Lacan que a noção de sujeito ganha status de conceito, de maneira que nos é possível afirmar que, enquanto o inconsciente é freudiano, o sujeito da psicanálise é lacaniano, como pontua Jorge (2017, p. 17): “a distinção categórica entre o eu e o sujeito do inconsciente foi estabelecida por Lacan, ao ressaltar que era justo no eu que Freud situava não apenas a instância produtora do recalque, como também a sede da maior resistência as descobertas analíticas”. Isso acontece a partir do movimento intitulado pelo próprio Lacan como retorno teórico a Freud, proposto no início de seu ensino, que foi uma contrapartida ao movimento dos pós-freudianos de definir o Eu em um funcionamento clínico que buscava seu fortalecimento, isto é, a tentativa de fundir a psicanálise com a psicologia geral, de manter o Eu centrado na consciência de forma a deixar o inconsciente em um segundo plano. Como tentativa de barrar esse movimento, Lacan também defendeu, assim com Freud, a desfiliação da psicanálise da medicina, por intermédio da prática leiga da psicanálise, ou seja, uma prática na qual não médicos pudessem exercer o ofício de psicanalista, de forma que a ênfase fosse maior na formação em psicanálise do que em medicina, visando a acabar com a vinculação da psicanálise a crenças e suposições típicas da medicina moderna. 
Lacaninicia ${ }^{10}$ sua articulação do sujeito a partir do estádio do espelho (LACAN, 1998, p. 96-103), que para ele é onde o ser humano tem seu primeiro contato com o campo do imaginário através de sua própria imagem, o que permite à criança se relacionar e experimentar o seu corpo e o mundo à sua volta. Isso se dá entre os seis e os dezoito meses de vida da criança, quando ela ainda não articula a fala nem a linguagem, e deve ser entendido com a transformação a partir da identificação produzida no sujeito quando ele assume uma imagem. De acordo com Câmara (2010, p. 22), Freud, ao dizer que o Eu é corporal, isto é, que é sobretudo uma projeção mental do corpo físico, não deixa clara a constituição do corpo imaginário, que é formado nas relações interhumanas, nas quais se precisa do outro para o reconhecimento. Nesse sentido, pode-se entender que é dessa abertura que Lacan parte para a formação do eu através do imaginário com sua dialética do estádio do espelho.

A apreensão da imagem especular na criança parece, segundo Lacan (1998, p. 97), manifestar a matriz simbólica em que o [eu ${ }^{11}$ se precipita de uma maneira primordial, isto é, antes de entrar na dialética de identificação com o outro e antes que a linguagem lhe empregue sua função de sujeito.Em outras palavras, o estádio do espelho situa a instância do eu desde antes de sua determinação social. Isso ocorre porque a forma total do corpo é antecipada em uma exterioridade que é mais constituinte do que constituída, de modo que essa antecipação permite a simbolização e a permanência mental do eu, além de configurar sua constituição alienada, uma vez que tal simbolização é o que une o indivíduo as suas fantasias, isto é, que une a consciência que enxerga sua imagem no espelho com o corpo que é identificado com essa imagem. $\mathrm{O}$ estádio do espelho também tem a função de estabelecer a relação do organismo com sua realidade, já que ele incita o reconhecimento "de uma insuficiência orgânica de sua

\footnotetext{
${ }^{10}$ De acordo com Barroso, a obra lacaniana pode ser dividida em três momentos, dos quais o primeiro tem como característica a centralidade do imaginário e seus efeitos; o segundo tem a primazia do simbólico e é marcado pela presença da linguagem e do significante; e no terceiro se faz presente a questão do corpo enquanto corpo de gozo, que se coloca como questão central para se pensar o inconsciente, de maneira que "abre-se aí o terceiro e último momento do ensino lacaniano, marcado pela noção de inconsciente real, que enfraquece a noção de inconsciente estruturado como uma linguagem" (BARROSO, 2012, p.155-156). Assim, à medida que a teoria lacaniana avança, o conceito de sujeito também sofre uma série de mudanças.

${ }^{11}$ Do original je, nas traduções consultadas aparece como [eu] de forma a diferenciar do eu da filosofia moderna que é encontrada na consciência. O je lacaniano faz referência justamente ao sujeito do inconsciente, já o moi, o eu que aparece através do estádio do espelho e que é o tema deste artigo, será empregado em sua forma comum: eu; de maneira que diferenciar do Eu em maiúsculo que faz referência ao Ich de Freud, e do [eu] lacaniano que faz referência ao sujeito da psicanálise.
} 
realidade natural" (LACAN, 1998, p. 99-100). Isso porque a relação do homem com a natureza é alterada por uma discórdia primordial que pode ser entendida como o malestar e a falta de coordenação motora da criança nos meses após o nascimento. Dessa maneira, o desenvolvimento do estádio do espelho é vivido como uma dialética que projeta a formação do sujeito, assim como salienta Lacan (1998, p. 100):

O estádio do espelho é um drama cujo impulso interno precipita-se da insuficiência para a antecipação- e que fabrica para o sujeito, apanhado do engodo da identificação espacial, as fantasias que se sucedem desde uma imagem despedaçada do corpo até uma forma de sua totalidade que chamaremos de ortopédica - e para a armadura assim assumida de uma identidade alienante, que marcará com sua estrutura rígida todo o seu desenvolvimento mental.

Por conseguinte, o momento no qual se conclui o estádio do espelho inaugura, pela identificação com a imagem do semelhante e pelo drama do ciúme primordial que remete ao Édipo, uma dialética que liga o eu a situações socialmente elaboradas. Esse é o momento que faz o saber humano, ou mais precisamente a consciência, direcionar-se para o desejo do Outro e faz do Eu um aparelho no qual qualquer impulso dos instintos será sentido como perigo. Assim, Lacan (2010, p. 56) introduz a noção de que "o eu, em seu aspecto mais essencial, é uma função imaginária”. De acordo com Faria (2011, p. 136), o que o imaginário faz é organizar e dar contorno ao real de forma ilusória, o que introduz a delimitação que separa o eu do não-eu. Ainda que ilusório, esse contorno imaginário é estruturante, e sem ele o real transbordaria e jamais seria simbolizado. A imagem do espelho faz o indivíduo situar num espaço imaginário o objeto que se acha além disso, na realidade. O objeto real, segundo Lacan (2010, p. 68) "não é o objeto que aparece no espelho. Há, pois, aí um fenômeno de consciência como tal.”, de forma que é razoável o entendimento de que o estádio do espelho faz referência ao nascimento da consciência no indivíduo, mais precisamente ao Eu freudiano. Contudo, o que Lacan visa a definir como sujeito vai em um sentido diferente daquilo que pode se observar na consciência.O sujeito lacaniano é aquilo que está mergulhado no discurso do inconsciente, de modo que ele está para além da consciência e do Eu que aparece a partir do estádio do espelho, consciente e imaginário, que é aquilo diante do qual o imediato da sensação é posto em tensão. Dessa maneira, o estádio do espelho deve ser 
entendido como a relação entre tendências descentradas do sujeito e tendências de unidade na qual o indivíduo se reconhece pela primeira vez. Todavia, como as tendências descentradas são ignoradas, a unidade na qual o sujeito se reconhece se faz como uma unidade alienante, como virtual.

Para Lacan (2010, p. 65), “o núcleo do nosso ser não coincide com o Eu”. Isso significa que a identidade ou a autoconsciência dos sujeitos está centrada na consciência, de forma que, segundo ele, pensar que o sujeito da psicanálise não está no $\mathrm{Eu}$ - isto é, não está na instância que Freud situa entre o pré-consciente e a consciência - não basta. Não se deve pensar que o Eu é uma forma incompleta ou errônea daquela que está no inconsciente, de forma que essa distinção é essencial à descoberta de Freud e acabar com o descentramento da identidade do sujeito seria um reducionismo para com a teoria freudiana. Segundo ele (LACAN, 2010, p. 65), esse reducionismo pode ser entendido como:

[...] a mesma diplopia que uma experiência bem conhecida dos oculistas demonstra. Coloquemos duas imagens muito próximas uma da outra e quase se recobrindo - graças a uma determinada vesguice, poderá ocorrer que formem apenas uma, se estiverem bastante próximas. Da mesma maneira, vocês fizeram entrar o eu nesse $[e u]$ descoberto por Freud - vocês restauraram a unidade.

Assim sendo, em Lacan, o eu não pode ser nada senão uma função imaginária, mesmo que isso determine a estruturação do sujeito. Até esse momento o sujeito é ninguém, é descomposto e despedaçado (LACAN, 2010, p. 79), de forma que se deixa aspirar pela imagem, enganar-se e realizar-se na imagem do outro ou em sua própria imagem especular. Contudo, o eu como função imaginária só intervém na vida psíquica, e o sujeito se coloca como operante, através da ordem do simbólico, e esse momento não é dedutível de nenhum modelo que seja da ordem de uma estruturação individual.

Assim como pontua Faria (2011, p. 144-145), a função organizadora do eu imaginário de Lacan, além de separar o eu do não eu através do contorno do real, é onde o sujeito encontra vazão para a linguagem e a ordem do simbólico, por meio de um outro contorno que forma as bordas do inconsciente ${ }^{12}$. A ordem no simbólico se impõe

\footnotetext{
${ }^{12}$ Essa passagem para linguagem que é possibilitada pelo eu imaginário, bem como o contorno do inconsciente, se tornam claros se analisada a exposição do caso Dick, apresentado no Seminário 1. 
através do discurso do Outro, do circuito no qual o sujeito participa simplesmente por não poder quebrar a cadeia do discurso. Ora, o sujeito veio ao mundo em meio a uma linguagem e uma cultura que ele não conhece, mas que necessita para participar, interagir e empregar sentido ao mundo à sua volta. Segundo Jorge (2017, p. 19), é essa ação que produz um sujeito que é ao mesmo tempo efeito da e sujeito à linguagem, por conta da sabedoria maior da língua. Esse eu que agora está no discurso e aparece em meio as relações inter-humanas se diferencia do eu especular imaginário, mas não o anula, porque a interação do eu com o outro sempre se dá no plano do imaginário, de forma que, a partir disso, as dimensões do simbólico e do imaginário se fazem entrelaçadas. Portanto, o movimento de situar o eu da psicanálise no campo do imaginário, proposto por Lacan, é uma tentativa de resolver a falta de definição dos conceitos relativos ao sujeito na teoria freudiana. Nas palavras de Lacan (2010, p. 200) "é evidente que se o termo imaginário tivesse podido ser empregado desde aquela época [primeira tópica], teria removido muitas contradições.”.

\section{CONSIDERAÇÕES FINAIS}

A partir da concepção do psiquismo dividido entre Eu, Id e Super-eu, o Eu é articulado por Freud como o intermediário daquilo que sai do inconsciente para o consciente. Isso porque o Eu parte do pré-consciente e isto permite a ele ligar-se tanto ao que é consciente quanto ao que é inconsciente, de maneira que é nele que os impulsos do Id encontram a saída para o mundo exterior. Assim, ele assume a função de direcionar o desejo e as pulsões do Id ao mundo exterior ao mesmo tempo que tenta adequá-los ao modo de funcionamento da realidade. No que diz respeito ao Super-eu, que é a agência descendente do Édipo, punitiva e vingativa, o Eu se vê controlado por sua consciência moral, que é resultado da internalização de seu ideal, e da figura paterna, além de ser responsável pela castração das pulsões e da agressividade. Dessa forma, o Eu proposto por Freud funciona como a superfície da estrutura psíquica, como algo que é sobretudo corporal e que é aquilo que tem de lidar com as exigências do

Todavia, como preferimos não abordar a questão do eu por intermédio da perspectiva das psicoses, decidimos não nos alongar nessa questão. 
mundo exterior, do Id e do Super-eu. Essa noção do psiquismo inicia o movimento de retirada do Eu do eixo percepção-consciência.

Entretanto, Lacan enxerga nos sucessores de Freud a tentativa de recolocar o Eu no eixo que vai da percepção até a consciência. Como contrapartida a esse movimento ele inicia o retorno teórico a Freud, que busca salientar a descoberta freudiana, ou seja, que o Eu está dividido entre a consciência e o inconsciente. Para isso, Lacan formula a dialética do estádio do espelho, na qual ele evidencia a formação do eu imaginário a partir do reconhecimento que é feito pela criança de sua imagem. Esse reconhecimento da imagem como um eu permite a construção mental e a delimitação do corpo, além da apreensão imaginária e consciente de um corpo que está no campo do real. O eu imaginário, do qual fala Lacan, tem a mesma função do Eu freudiano, ou seja, o eu que surge do estádio do espelho não é nada mais do que o eu consciente, já que para o psicanalista francês o sujeito da psicanálise é o sujeito inconsciente. Sabe-se, porém, que, mesmo que Lacan chame seu movimento de retorno a Freud, ele acaba se distanciando dos conceitos freudianos e formulando seus próprios, de modo que desde o início de seu ensino pode-se perceber a presença de uma psicanálise lacaniana. Sendo assim, nos é lícito o entendimento de que enquanto o psiquismo de Freud inaugura o inconsciente, o de Lacan inaugura um sujeito inconsciente que é dividido entre o indivíduo real e o eu imaginário, o sujeito da psicanálise.

\section{BIBLIOGRAFIAS}

BARROSO, Adriane de Freitas. Sobre a concepção de sujeito em Freud e Lacan. Barbarói, n. 36, p. 149-159. Santa Cruz do Sul, jan./jun. 2012.

BURGARELLI, Cristóvão Giovani. Sobre o sujeito da psicanálise. Estilos da Clínica, v. 12, n. 23, p. 214-223. São Paulo, 2007.

CÂMARA, Gabriel Ferreira. A formação do eu e o poder da psicanálise. Cógito, n. 11, p. 20-25. Salvador, out. 2010.

FARIA, Michele Roman. Imaginário eu e psicoses nos primeiros seminários de Lacan. Estilos da Clínica, v. 16, n. 1, p.132-151. São Paulo, 2011.

FREUD, Sigmund. Projeto de uma psicologia. Trad. Osmyr Faria Gabbi Junior. Rio de Janeiro: Imago, 1995. 
FREUD, Sigmund. Sigmund Freud - obras completas volume 16: O eu e o Id, "autobiografia" e outros textos (1923-1925). Trad. Paulo César de Souza. São Paulo: Companhia das Letras, 2011.

FREUD, Sigmund. Sigmund Freud - obras completas volume 14: História de uma neurose infantil ("o homem dos lobos"), além do princípio do prazer e outros textos (1917-1920). Trad. Paulo César de Souza. São Paulo: Companhia das Letras, 2010 .

JORGE, Marco Antonio Coutinho. Lacan com Freud: A psicanálise hoje. Reverso, n. 73, p. 15-26. Belo horizonte, jun. 2017.

LACAN, Jacques. Escritos. Trad. Vera Ribeiro. Rio de Janeiro: Jorge Zahar, 1998.

LACAN, Jacques. O seminário livro 2: O eu na teoria de Freud e na técnica da psicanálise. Trad. Marie Laznik Penot e Antônio Quinet. 2. ed. Rio de janeiro: Zahar, 2010.

ŽIŽEK, Slavoj. Como Ler Lacan. Trad. Maria Luiza X. de A. Borges. Rio de Janeiro: Zahar, 2010. 